\title{
EVOLUÇÃO HISTÓRICA DO DIREITO DE FÉRIAS NO BRASIL
}

\author{
HISTORICAL EVOLUTION OF VACATION RIGHTS IN BRAZIL
}

Gustavo Dias Motta ${ }^{1}$

\section{RESUMO}

O artigo analisa a evolução do direito de férias no Brasil, partindo de sua instituição até os dias atuais, após as alterações da reforma trabalhista da Lei $n^{\circ} 13.467 / 17$. Através de pesquisa do histórico legislativo, bem como da doutrina relacionada, verificou-se que houve uma trajetória de progressivo detalhamento e melhora de aspectos do direito de férias, mas tímida no que se refere à sua amplitude e prestígio à autonomia de vontade dos trabalhadores. Realizadas em contextos paternalistas e/ou autoritários, as alterações se circunscreveram a aperfeiçoar aspectos originais e pré-determinados, sem abertura para diálogo ou reformulação ampla, capazes de melhorar efetivamente a qualidade do direito.

Palavras-chave: Férias. Descanso Anual Remunerado. Evolução Histórica. Reforma Trabalhista.

\begin{abstract}
This article analyzes the evolution of vacation rights in Brazil, starting from its institution to the present day, after the changes of the Labour Reform by the 13.467/17 Act. Through research on the legislative history and related doctrine, it was found that there was a progressive detailing and improvement on some entitlements of vacation rights, but timid in terms of its breadth and prestige to the workers' autonomy of will. Taken in paternalistic and / or authoritarian contexts, the changes were limited to perfecting original and predetermined aspects, without openness to dialogue or broad reformulation, capable of effectively improve the quality of rights.
\end{abstract}

Palavras-chave: Vacation. Holiday. Historical Evolution. Labour Reform.

Sumário: Introdução; 1- Surgimento do Direito de Férias; 1.1- No Mundo; 1.2- No Brasil; 2Desenvolvimento do Direito de Férias no Brasil; 2.1- O Decreto-Lei ${ }^{\circ} 5.452$, de $1^{\circ}$ de maio de 1943 - A Consolidação das Leis do Trabalho; 2.2- A Lei nº 816, de 09 de setembro de 1949; 2.3- O Decreto-Lei ${ }^{\circ} 1.535$, de 15 de abril de 1977; 2.4- A Constituição Federal de 1988; 3Atualidade do Direito de Férias no Brasil - A Reforma Trabalhista da Lei no 13.467/17; Conclusão; Referências.

\section{INTRODUÇÃO}

Em 13 de julho de 2017 foi sancionada a Lei $\mathrm{n}^{\circ}$ 13.467, que, conforme ementa, visa “adequar a legislação às novas relações de trabalho" (BRASIL, 2017). Dentre as diversas

\footnotetext{
${ }^{1}$ Advogado. Pós-graduado em Gestão de Recursos Humanos pela Universidade Federal Fluminense (UFF).
} 
alterações conduzidas por esta lei, está uma nova disciplina para o exercício das férias.

A nosso juízo, tais modificações receberam pouca atenção, bem como tratamento superficial por parte da doutrina. As discussões sobre o tema estiveram demasiadamente focadas na comparação do texto imediatamente anterior da CLT, a ser revogado, e aquele que se implementou. Não tivemos notícia de estudos aprofundados que analisassem as atuais mudanças sob uma perspectiva mais ampla e histórica, que contemplasse a evolução do direito de férias no Brasil, desde sua criação até os dias atuais.

Consideramos essencial uma análise evolutiva desse direito trabalhista, capaz de perpassar por suas mudanças e permanências ao longo da história, descortinando sua transformação no tempo. Para nós, esse panorama soa fundamental ao efetivo conhecimento e valoração das mudanças atualmente introduzidas, pois, como se pode julgar o estado atual de coisas se sequer se sabe de onde se partiu exatamente?

Com efeito, é preciso pensar o passado para compreender o presente e idealizar o futuro, disse Heródoto há mais de dois mil anos, na Grécia. Somente se pode chegar a uma conclusão quanto às novas regras de férias introduzidas pela reforma trabalhista quando se conhece a evolução no tempo do direito de férias no Brasil. Assim, seremos então capazes de perceber, e responder, se o que foi modificado representa o atendimento de demandas do trabalhador ou do empregador, ou, ainda, se de fato constituem pautas importantes ou não, finalmente atendidas; se são demandas antigas ou recentes na matéria; enfim, se houve avanço/incremento do direito, mera estabilidade, ou puro retrocesso.

Munido do escorço histórico e respondidas estas perguntas, finalmente, se poderá, quem sabe, chegar a um juízo de valor responsável acerca da reforma trabalhista, na parte que trata do direito de férias, considerando-a virtuosa ou não. Analisar a evolução do direito de férias no Brasil, portanto, partindo de seu surgimento, desenvolvimento e atualidade, permitirá chegar a uma melhor conclusão quanto ao seu patamar atual, pós-reforma.

Assim, o presente estudo busca revelar, através de pesquisa do histórico legislativo, bem como dos apontamentos da doutrina relacionada, quando, como e em que nível o direito de férias surgiu no mundo, passando ao caso específico da sua previsão inicial no Brasil, sua evolução ao longo do tempo, influências, avanços e retrocessos, findando no estágio atual da legislação, recentemente alterada pela Lei no ${ }^{\circ} 13.467 / 17$.

\section{2- SURGIMENTO DO DIREITO DE FÉRIAS}

\section{1- No Mundo}

O Brasil não foi pioneiro na previsão de um direito de férias. Assim, antes de examinarmos o surgimento da garantia no Brasil, julgamos conveniente analisar o nascimento das férias no plano mundial.

O direito de férias constitui uma criação recente, como também é o próprio Direito do Trabalho. Sua origem formal remonta às Revoluções Industriais Europeias dos séculos XVIII, XIX e XX, período em que o labor migrou progressivamente do trabalho no campo e de manufaturas artesanais organizadas sob a forma de corporações de oficio, para a escala industrial de grandes fábricas, de trabalho repetitivo, controlado e assalariado (DELGADO, 2009; HOBSBAWM, 1986).

O intenso avanço tecnológico do período permitiu um extraordinário crescimento da produção e seu acúmulo, todavia, não tornou o trabalho, em si, mais seguro ou menos desgastante à nova classe do proletariado. Ao contrário, houve intensificação do uso da mão de obra, inclusive de mulheres e crianças, da jornada de trabalho, e da forma de execução das atividades, que passaram a consistir em movimentos repetitivos por período incessante (MONTEIRO; GOMES, 1998). 
As típicas indústrias motrizes da época, têxtil, metalurgia e exploração de carvão, não obstante inseridas no processo de mecanização, permaneceram atividades notavelmente exaustivas para o trabalhador e não havia qualquer moldura legal ou jurídica capaz de limitar eventuais abusos (BEAUD, 2005). Não se cogitava, ainda, uma relação-modelo de trabalho entre empregador e empregado, específica e regulada pelo Estado. Uma omissão que permitiu acordos particulares regidos pelo direito civil, com ampla liberdade de pactuação, mas que redundavam, na prática, no estabelecimento unilateral das condições de trabalho pelo empresariado, sem limites de tempo, intervalos para descanso ou patamares mínimos de dignidade (MARTINS, 2000).

Diante do evidente desgaste físico de alguns trabalhadores, recorrência de acidentes e clima de insatisfação progressiva, determinados industriais se anteciparam e passaram a conceder informalmente, e por pura liberalidade, a alguns operários, o benefício de descansar remuneradamente por um certo período de tempo. Tratava-se, porém, de exceção dentro do quadro geral de degradação das condições de vida da população trabalhadora (RUSSOMANO, 2006).

O compartilhamento da insatisfação, discutido em grandes aglomerações de pessoal nas fábricas, acabou levando a um associativismo, que ganhou caráter combativo para a obtenção de melhorias. $\mathrm{O}$ sindicalismo e suas reivindicações se concentraram primeiramente no âmbito das fábricas, mas depois avançaram sobre o próprio espaço público, gerando assim grande atenção e temor pelo empresariado e pelas autoridades. Em alguns locais, como a França, por exemplo, houve o seu ressurgimento clandestino, uma vez que a Lei Chapelier proibia expressamente seu funcionamento desde 1791. Não obstante as dificuldades, demandas como a por moderação da jornada de trabalho e oferecimento de intervalos obrigatórios para descanso se tornaram pautas comuns e essenciais (ANTUNES, 1985).

A disseminação de greves e turbulência político-institucional acabou impondo aos Estados uma progressiva participação na questão do trabalho, o que levou à previsão legal de alguns direitos mínimos, dentre eles, as férias, porém, ainda restrita a diferentes categorias profissionais e econômicas, sobretudo aquelas dotadas de maior poder de influência junto ao empresariado e ao poder público. Como o processo não se deu de maneira uniforme no mundo, seu marco inicial é controvertido. Há quem aponte para períodos antigos, como 1821, na Dinamarca, em que já seria garantida, por lei, 1 (uma) semana de férias aos domésticos (GIGLIO, 1978). Ou ainda, para 1853, na França, quando os funcionários públicos tinham direito a 15 (quinze) dias de férias (NUNES, 2017). Outros destacam a importância da promulgação, em 1872, na Inglaterra, de uma lei garantindo férias a todos os operários da indústria (MARTINS, 2008). De qualquer forma, nesta fase o direito de férias ainda não era amplo e garantido à totalidade dos trabalhadores empregados.

Posteriormente, em 1891, a Igreja Católica proclama a encíclica Rerum Novarum, com críticas à situação de injustiça social e recomendações de intervenção dos Estados como meio legítimo para se coibirem os abusos do poder econômico sobre o trabalho (inclusive de jornada). Defendia-se a necessidade de períodos de descanso (COIMBRA, 2014).

No início do século XX há, então, uma fase de expansão do benefício pelo mundo, englobando progressivamente mais trabalhadores. As férias passam à condição de direito geral subjetivo, exigível mediante injunções, uma vez que positivado tanto em normas internas como internacionais. Esta fase de ampliação e consolidação do direito no mundo se deve, em grande medida, ao contexto econômico-político e social do final da Primeira Guerra Mundial, cujo acordo de paz (Tratado de Versalhes) previu a criação de uma Organização Internacional voltada à discussão e defesa de patamares mínimos aos trabalhadores, como forma de promoção da paz e redução das tensões sociais. Como pano de fundo estavam os acontecimentos de 1917 na Rússia, uma revolução cujo protagonismo partiu de uma classe trabalhadora descontente (DUPPER, 2015). 
Criada em 1919, a Organização Internacional do Trabalho (OIT) busca, por meio de convenções e recomendações, pressionar os países a promulgar regulamentações internas capazes de elevar efetivamente as condições mínimas do trabalho (OIT BRASILIA, 2017). Com esta missão impulsionou-se a criação do direito de férias nas legislações internas dos países membros e, depois, a edição de convenções internacionais na matéria.

Assim, em 1919 a Áustria promulga sua primeira lei concedendo o direito de férias à totalidade dos trabalhadores assalariados (BARROS, 2001). Entre 1919 e 1925, também Finlândia, Itália, Tchecoslováquia e Polônia concederam férias a operários, mineiros e jornalistas. Entre 1926 e 1934, Luxemburgo, Grécia, Romênia, Chile, México, Espanha, Suécia, Portugal também legislaram sobre o tema. Em 1936, França, Iraque, Bélgica e Bulgária. Ou seja, as férias pagas foram efetivamente instauradas em diversos países por volta dos anos trinta (NUNES, 2017). Em 1938 eram 40 os países que possuíam legislação nesse sentido (BARROS, 2001). A maioria dos trabalhadores, porém, só ganhou acesso pleno ao direito após a Segunda Guerra Mundial (OIT BRASILIA, 2017).

O primeiro documento da OIT sobre férias foi a Convenção $\mathrm{n}^{\circ} 52$, aprovada na $20^{\mathrm{a}}$ reunião em Genebra, em 1936. Ratificada pelo Brasil, em 1938, previa como patamar mínimo dos trabalhadores dos Estados partícipes, o direito a férias remuneradas de seis dias úteis. Ainda em 1936 foi editada pela OIT a Recomendação $n^{\circ}$ 47, sugerindo, entre outras coisas, que o período aquisitivo das férias não deveria ser afetado por interrupções decorrentes de enfermidade, exercício de direitos cívicos, acontecimentos familiares, serviço militar e outros; e, que ainda que o fracionamento das férias pudesse ser conveniente em casos especiais, que não se deveria permitir mais que dois fracionamentos do período; que seria apropriado o aumento do período de férias conforme a antiguidade no serviço etc. (OIT BRASILIA, 2017).

Em 1948 a Declaração Universal dos Direitos Humanos, proclamada pela Assembleia Geral da ONU, previu que: "Art.24: Toda a pessoa tem direito ao repouso e aos lazeres e, especialmente, a uma limitação razoável da duração do trabalho e a férias periódicas pagas" (NAÇÕES UNIDAS BR, 2017).

Em 1949 foi editada a Convenção de Férias Remuneradas específica para os Marítimos e em 1952 a Convenção de Férias Remuneradas específica para os Agrícolas (OIT BRASILIA, 2017). Em 1970 a OIT aprovou na sua 54 ${ }^{\mathrm{a}}$ reunião, em revisão aos documentos anteriores, a Convenção $\mathrm{n}^{\circ}$ 132, tratando de férias remuneradas dos trabalhadores (à exceção dos marítimos) (OIT BRASILIA, 2017).

Posteriormente, em 1966, foi previsto no Pacto Internacional sobre Direitos Econômicos, Sociais e Culturais o direito de toda pessoa de gozar de condições de trabalho justas e favoráveis, que assegurem especialmente: “Art. $7^{\circ}$ : d) O descanso, o lazer, a limitação razoável das horas de trabalho e férias periódicas remuneradas, assim como a remuneração dos feriados (NAÇÕES UNIDAS BR, 2017).

O direito às férias também foi previsto em nível de sistemas regionais. Desde 1988, no âmbito da Organização dos Estados Americanos (OEA), o direito às férias consta do Protocolo de San Salvador, adicional à Convenção Interamericana de Direitos Humanos (Pacto de San José da Costa Rica), ao se afirmar que os Estados aderentes garantirão em suas legislações, de maneira particular: "Art. $7^{\circ}, \mathrm{h}$ ) repouso, gozo do tempo livre, férias remuneradas, bem como remuneração nos feriados nacionais" (CIDH ORG, 2017). Direito semelhante consta, também, desde 1996 da Carta Social Européia, que garante um período anual de férias pagas de quatro semanas, pelo menos, bem como desde 2000, da Carta Comunitária dos Direitos Sociais Fundamentais dos Trabalhadores Europeus ("todos os trabalhadores tem direito a um período anual de férias pagas”) (DA SILVEIRA, 2006).

\section{2- No Brasil}


O direito às férias no Brasil passou por surgimento e evolução semelhantes aos verificados no plano internacional. Também principiou sendo concedido por mera iniciativa pontual de alguns industriais. Neste sentido, há notícia de empresários como Luis Tarquino, na Bahia, em 1891, e Jorge Street, em São Paulo, em 1917, que chegaram a conceder a benesse por exclusiva liberalidade (BARROS, 2001).

Com a crescente mobilização dos trabalhadores por melhores condições de trabalho, o Estado brasileiro foi então, paulatinamente, fazendo concessões à categorias específicas através de leis esparsas, passando, posteriormente, à regulação do direito de férias para uma parcela maior dos trabalhadores urbanos. Nesta toada, se em 1889 eram garantidas, através de Aviso Ministerial específico, férias anuais remuneradas de 15 (quinze) dias, apenas, aos trabalhadores do Ministério da Agricultura, Comércio e Obras Públicas, já, em 1890 o direito restou ampliado aos operários diaristas e ferroviários e, mais tarde, a todos os empregados de estabelecimentos comerciais, industriais e bancários, por meio da Lei no 4.982/1925 (CASSAR, 2011).

Promulgada na esteira de outras regulamentações concebidas pela recém-criada Confederação Nacional do Trabalho (Decreto $\mathrm{n}^{\circ}$ 16.027/1923), órgão de governo com o objetivo de oferecer "consulta aos poderes públicos em assuntos referentes à organização do trabalho e da previdência social", esta primeira lei de férias mais ampla passou a garantir a todos os trabalhadores urbanos o direito a 15 (quinze) dias de férias remuneradas anuais. O Brasil foi o sexto país do mundo a estender o direito a todos os empregados e operários de empresas privadas (SÜSSEKIND, 1977). Esta posição de vanguarda, porém, durou pouco. A Lei no 4.982/25 gerou severas críticas do patronato, sobretudo industrial, que considerou inviável e inadmissível a concessão do direito de tal forma ampla, tendo se recusado frontalmente a dar cumprimento ao direito.

De modo que, em 1931, sob o governo Vargas e seu recém-criado Ministério do Trabalho, Indústria e Comércio (instituído pelo Decreto $\mathrm{n}^{\circ}$ 19.770/1931) houve a suspensão da execução da norma pelo Decreto ${ }^{\circ} 19.808 / 1931$. Momento em que a normatização das férias retornou ao estágio antecedente dos particularismos por categoria (comerciários, industriais etc.), sendo permitido para alguns, por exemplo, o parcelamento em mais de dois períodos, de no mínimo três dias, enquanto que para outros este era completamente vedado (NUNES, 2017).

Em 1933 foi editado o Decreto $\mathrm{n}^{\circ}$ 23.103, regulando a concessão de férias aos empregados em estabelecimentos comerciais e bancários e em instituições de assistência privada. Em 1934 foi editado o Decreto $\mathrm{n}^{\mathrm{o}}$ 23.768, destinado aos empregados em estabelecimentos de qualquer natureza, modalidade ou ramo de atividade industrial, empresas jornalísticas, de comunicações e transportes terrestres e aéreos e de serviços públicos. Tratavase de outra tentativa de concessão ampla do direito de férias (à várias categorias distintas), porém, dentro do projeto Varguista, passou a ser exigida a sindicalização dos empregados para se fazer jus ao direito. No mesmo ano, as férias ganharam também previsão na Constituição de 1934 (BARROS, 2001).

Uma síntese desta evolução legislativa apresentada até o presente momento pode ser visualizada na Tabela 1 anexa ao final deste trabalho.

\section{DESENVOLVIMENTO DO DIREITO DE FÉRIAS NO BRASIL - CLT E CF/88}

\section{1- O Decreto-Lei $n^{0}$ 5.452, de $1^{\circ}$ de maio de 1943 - A Consolidação das Leis do Trabalho}

Já em 1943, com o advendo da CLT, que sistematizou legislações esparsas, estendeu-se finalmente o direito de férias à maioria dos trabalhadores empregados, inclusive aos rurais, mas ainda excluindo os avulsos e domésticos da garantia (estes últimos só passariam a gozar efetivamente deste direito em 1972, com o advento da Lei $\mathrm{n}^{\circ}$ 5859).

A CLT original garantia 15 (quinze) dias úteis de férias aos empregados, após período 
aquisitivo de 12 (doze) meses à disposição do empregador; 11 (onze) dias úteis, aos que tivessem ficado à disposição do empregador por mais de 200 (duzentos) dias; 7 (sete) dias úteis aos que tivessem ficado à disposição do empregador menos de 200 (duzentos) e mais de 150 (cento e cinquenta) dias.

Previa também que as férias seriam sempre gozadas no decurso dos doze meses seguintes à data em que o empregado as tivesse adquirido, sendo vedada a acumulação.

Era admitido o fracionamento excepcional das férias em até 2 (dois) períodos, sendo que um deles não podia ser inferior a 7 (sete) dias. A época do gozo, isto é, a escolha quanto a sua data inicial, era a que melhor consultava aos interesses do empregador.

Aos menores de 18 anos e aos maiores de 50 anos de idade, as férias eram sempre concedidas de uma só vez. A concessão das férias era participada, por escrito, com a antecedência, no mínimo, de 8 (oito) dias. Dessa participação o interessado dava recibo.

\section{2- A Lei ${ }^{0}$ 816, de 09 de setembro de 1949 - Ampliação do número de dias de férias e do rol de faltas justificadas}

Em 1949, após o Estado Novo de Vargas, já, no governo de Eurico Gaspar Dutra, é editada a Lei $\mathrm{n}^{\circ} 816$, que consiste basicamente em um normativo através do qual se incluiu a previsão de que o período de férias passaria para vinte dias úteis se o empregado não tivesse faltado mais de seis vezes ao serviço no período aquisitivo, justificadamente ou não.

Além disso, houve também uma ampliação das hipóteses de não desconto do período aquisitivo de férias, passando a constar como justificável o tempo de suspensão por motivo de inquérito administrativo (quando o mesmo fosse julgado improcedente), bem como as hipóteses legais de não comparecimento ao trabalho constantes do art.473 (remissão que permanece válida até os dias atuais), quais sejam, situações específicas de licenças autorizadas, como o falecimento de cônjuge, ascendente, descendente, irmão ou pessoa que vivesse sob sua dependência econômica; ou ainda a hipótese de nascimento de filho.

\section{3 - O Decreto-Lei no 1.535, de 15 de abril de 1977 - Reformulação do Capítulo IV do Título II da CLT, que trata das Férias}

Em 1977, durante o governo militar de Ernesto Geisel, é editado o Decreto-Lei n ${ }^{\circ} 1.535$, reorganizando todo o capítulo responsável pelo tratamento das férias na CLT. Grande parte das alterações conduzidas nessa oportunidade tem por inspiração a Convenção 132 da OIT, concluída em 1970, relativa às férias dos trabalhadores em geral (exceto a categoria dos marítimos, regida especificamente neste tema pela posterior Convenção 146 da OIT). A Convenção 132 da OIT, aliás, subsiste até os dias atuais como principal norma de férias da sociedade internacional.

Assim, muito embora o Brasil só tenha se tornado signatário do referido documento internacional em 1997 (com entrada em vigor de suas disposições em 1999, pelo Decreto Presidencial n ${ }^{\circ}$ 3.197), a modificação da CLT, na prática, já a havia tornado comparativamente próxima (ou até mais benéfica em alguns pontos) do que a própria Convenção 132, que visava estabelecer patamares mínimos do direito de férias. Por outro lado, ainda se continuou possível encontrar temas pontuais em que a Convenção poderia oferecer regra mais benéfica do que a CLT.

Nesse sentido, aliás, houve até bem pouco tempo discussão judicial acerca da aplicabilidade da norma interna, internacional, ou até mesmo de ambas em determinados casos concretos. A controvérsia só chegou a termo com a adoção, pela jurisprudência do Tribunal Superior do Trabalho (TST), da teoria do conglobamento, que entendeu pela prevalência da 
norma interna (CLT) como a norma exclusiva a ser aplicada no Brasil, pois mais favorável em seu conjunto (BARROS, 2001). Isso significa, na prática, na impossibilidade de se pinçar as regras mais convenientes de cada um dos diplomas envolvidos (tese da acumulação).

Exemplo deste posicionamento do TST foi a edição do Enunciado $n^{\circ} 171$ de sua Súmula, que entendeu não serem devidas férias proporcionais aos empregados demitidos por justa causa, tese desfavorável ao trabalhador, mas que prestigiou a CLT como a norma mais benéfica no conjunto de direitos rescisórios.

A Convenção $\mathrm{n}^{\circ} 132$ da OIT prevê, àqueles a quem se aplica, patamares mínimos. Dentre eles, pode-se citar: o direito a pelo menos 3 (três) semanas de descanso remunerado a cada ano de trabalho; o direito a férias proporcionais, em caso de período inferior a 1 (um) ano de serviço. Prevê também que os feriados oficiais ou costumeiros não serão computados como parte do seu período. Que a época das férias será determinada pelo empregador após consulta com o empregado interessado, sendo levadas em conta as necessidades do trabalho e as possibilidades de repouso e diversão, segundo conveniência do empregado. Que o fracionamento é possível, mas o período mínimo de descanso contínuo deverá corresponder a pelo menos a 2 (duas) semanas de trabalho ininterruptas. Que a parte ininterrupta do período de férias deverá ser outorgada e gozada dentro de, no máximo, 1 (um) ano, sendo o restante do período necessariamente dentro dos próximos 18 (dezoito) meses, a contar do fim do período aquisitivo. Que todo acordo relativo ao abandono do direito ao período mínimo de férias ou renúncia ao seu gozo mediante indenização ou qualquer outra forma, será, dependendo das condições nacionais, nulo de pleno direito (OIT BRASILIA, 2017).

Já a CLT, na redação do Decreto-Lei no 1.535, de 15 de abril de 1977, passou a prever uma proporção mais gradual de dias de férias conforme o número de faltas não justificadas ocorridas no período aquisitivo. Também o período máximo de férias passou a ser de 30 (trinta) dias corridos, caso o empregado não tenha faltado injustificadamente ao serviço mais de 5 (cinco) vezes. Ou seja, houve melhora nesse aspecto, bem como deixaram de ser punidas as faltas justificadas no cômputo devido.

Não houve alteração substancial quanto ao rol de faltas justificadas, bem como de causas que levam a perda do direito de férias. Houve mera reorganização dos dispositivos da legislação nestes pontos. Com relação à concessão das férias passou-se a prever que, dentro da excepcionalidade de dois períodos, um deles não deveria ter menos de 10 (dez) dias corridos, prazo maior do que o da redação original da CLT que indicava como período mínimo de descanso contínuo 7 (sete) dias corridos. Não houve mudança quanto a regra original da CLT que determinava que as férias dos menores de 18 (dezoito) e maiores de 50 (cinquenta) anos de idade deveriam ser concedidas em um único período. Foi também modificado o prazo de antecedência para participação ao empregado de suas férias, que passou para 10 (dez) dias, enquanto que na CLT original o prazo era de 8 (oito) dias. Na verdade, este prazo acabou sendo alterado posteriormente pela pontual Lei $\mathrm{n}^{\mathrm{o}} 7.414 / 85$, que determinou que a antecedência seja de, no mínimo, 30 (trinta) dias, o que se mantém até hoje. Quanto à época da concessão das férias esta continuou sendo exclusivamente a que melhor consulte os interesses do empregador. Única melhoria neste sentido foi a introdução da garantia ao empregado estudante, menor de 18 (dezoito) anos, que passou a ter direito de fazer coincidir suas férias com as férias escolares, o que não havia na CLT original.

O Decreto-Lei ${ }^{\circ} 1.535 / 77$ inseriu e detalhou ainda diversos outros aspectos que a CLT original não cuidou como, por exemplo, uma especificação de penalidades pela não concessão das férias no prazo oportuno (pagamento em dobro da remuneração). Foram também previstas medidas destinadas ao efetivo cumprimento do direito de férias, como a previsão de ajuizamento de reclamação, passível de importar em multa diária de 5\% do salário regional. Houve, também, aparente procupação com o efetivo descanso do trabalhador, mas que redundou em norma, a nosso sentir, inócua, ao se proibir que o empregado prestasse serviços a 
outro empregador durante as férias, salvo se estiver obrigado a fazê-lo em virtude de contrato de trabalho regularmente mantido com aquele.

Além disso, foi previsto pelo DL também toda a normativa de férias coletivas (arts.139/141), o que não foi previsto na CLT original. Estabeleceu-se que podem ser concedidas à totalidade dos trabalhadores ou parcialmente, por estabelecimento ou setor da empresa, em até 2 (dois) períodos anuais nunca inferiores a 10 (dez) dias corridos. O empregador comunicará ao órgão local do Ministério do Trabalho e Emprego e ao sindicato dos trabalhadores, com antecedência mínima de 15 dias, o início e o fim destes períodos de férias coletivas.

Destaquem-se, por fim, as novas disposições relativas à remuneração e ao abono das férias, que passaram a permitir a conversão pelo empregado de 1 (um) terço de suas férias em abono pecuniário, opção jurídica que deve ser requerida em até 15 (quinze) dias antes do término do período aquisitivo. O pagamento das férias também passou a ser feito até 2 (dois) dias antes do seu início.

Uma síntese desta evolução legislativa apresentada até o presente momento pode ser visualizada na Tabela 2 anexa ao final deste trabalho.

\section{4 - A Constituição Federal de 1988}

Com a Constituição Federal de 1988 os direitos sociais dos trabalhadores foram elevados a um novo patamar, restando estampado no art. $7^{\circ}$, XVII da magna carta o direito ao gozo de férias anuais remuneradas acompanhadas de um terço a mais do que o salário normal, benefício conhecido como "terço constitucional de férias" (MARTINS, 2008). A principal novidade trazida pela Constituição atual no tema foi, portanto, este acréscimo de um terço na remuneração do trabalhador, não podendo o mesmo renunciar a esse direito.

\section{ATUALIDADE DO DIREITO DE FÉRIAS NO BRASIL - A REFORMA TRABALHISTA DA LEI No 13.467/17}

A Lei $n^{\circ} 13.467 / 17$ efetuou reformas pontuais no direito de férias. Não houve modificação substancial das regras, tampouco reorganização das disposições no capítulo, como ocorreu, por exemplo, com a reforma anterior do DL $\mathrm{n}^{\circ} 1535 / 77$, como vimos. A presente reforma se concentrou, portanto, em alterar determinados aspectos relacionados ao gozo das férias, sua época e forma de fruição, como veremos com detalhes nesta seção.

A única alteração que não se enquadra nesse paradigma foi aquela ocorrida fora do capítulo que trata das férias, mas relacionada ao tema, que foi a ampliação do tempo de férias dos trabalhadores empregados em tempo parcial, que passaram a gozar também de 30 (trinta) dias de férias como os demais empregados. Anteriormente havia uma redução proporcional no seu período de férias tendo em vista que não laboravam na jornada comum integral.

Também foi estendida aos trabalhadores em tempo parcial a faculdade de venda de um

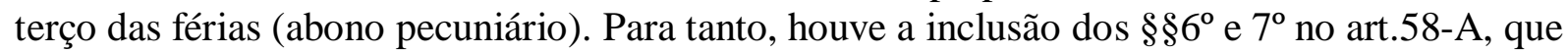
é o dispositivo que trata desta forma específica de jornada de trabalho. Neste ponto, o tratamento das férias foi remetido ao art.130 da CLT, que trata dos períodos de aquisição de férias dos trabalhadores em geral, de jornada integral.

Assim, hoje, após a reforma trabalhista, também são assegurados aos trabalhadores empregados em tempo parcial 30 (trinta) dias corridos de férias (caso faltem injustificadamente no máximo até cinco vezes durante o período aquisitivo), sem prejuízo da remuneração. 
Outra inovação da Lei $n^{\circ}$ 13.467/17 (Reforma Trabalhista) se deu sobre a possibilidade de fracionamento e duração dos períodos de gozo de férias. Agora, os 30 (trinta) dias de férias passam a poder ser fracionados em até 3 (três) períodos, sendo que antes havia a limitação a 2 (dois) períodos, no máximo. Além disso, os períodos mínimos de gozo das férias foram ampliados, devendo atualmente um deles, o principal, não ser inferior a 14 (quatorze) dias corridos e os demais a 5 (cinco) dias corridos, cada um (caso seja adotado o triplo fracionamento). Anteriormente, vale lembrar, o período principal deveria ter, no mínimo, a duração de 10 (dez) dias (o segundo, por óbvio ou tinha os vinte dias restantes ou dez, em caso de decisão pela venda e recebimento do abono pecuniário).

Outra alteração se deu sobre a época das férias, tendo sido inserida vedação de início do período de férias nos 2 (dois) dias que antecedem feriado ou o dia de repouso semanal remunerado. Ou seja, com a reforma, houve uma limitação substancial, a pretexto de beneficiar o trabalhador, nas datas possíveis de marcação das férias, sendo oportuno relembrar que a época das férias é (e permanece) ao alvedrio exclusivo do empregador, na forma do art.136, CLT, inalterado.

Por fim, a reforma revogou o anterior impedimento à bipartição das férias por trabalhadores menores de 18 (dezoito) anos e maiores de 50 (cinquenta) anos de idade, não mais subsistindo, hoje, tal vedação.

Na prática, todas estas regras constavam do art.134, CLT e seus parágrafos, sendo esse, portanto, o dispositivo que concentra a maioria das alterações no tema das férias pela reforma trabalhista da Lei no 13.467/17.

Analisando de maneira crítica e comparativa as mudanças conduzidas pela presente reforma trabalhista, vale destacar que o aumento na possibilidade de fracionamento do período de férias para 3 (três) não representa, à priori, melhoria ou piora ao trabalhador, pois pode ser do seu interesse ter maior maleabilidade. A própria Convenção 132 da OIT não limita fracionamentos.

Felizmente foi conservado (ou melhor, evidenciado) que a escolha pelo fracionamento do período compete ao empregado. Do contrário, juntamente com a manutenção da escolha da época das férias nas mãos exclusivas do empregador, poderia ser extremamente danoso ao empregado. A propósito, a escolha da época das férias pelo empregador, sem qualquer consulta ao empregado, é um ponto que merecia modificação (art.136 da CLT), como aliás, dispõe a Convenção 132 da OIT e o fazem diversos países, tal qual Portugal, que previu que seja levado em consideração o interesse do empregado na definição da época das férias.

Com relação à ampliação da duração do período principal de férias para, no mínimo, 14 (quatorze) dias corridos, e a fixação dos demais em 5 dias corridos, é oportuno destacar que houve um alinhamento ao período mínimo previsto na Convenção 132 da OIT, que estabelece uma duração mínima de 2 (duas) semanas num dos períodos. Tal modificação pode (e tem sido encarada) como positiva, pois de fato amplia o período de descanso contínuo do empregado, possibilitando a este obter, pelo menos em tese, um descanso mais duradouro. Ressalvamos, todavia, nossa opinião, de que esse tipo de definição apriorística, de natureza paternalista, vai de encontro aos interesses de grande parte dos empregados, que buscam liberdade e maleabilidade na definição de seu período de férias. Reafirmamos que, à nosso juízo, muito mais importante aos trabalhadores, seria permitir que estes pudessem influenciar ou mesmo definir a época de suas férias, ao que poderia ser acrescentado também seu número de fracionamentos e período de duração, garatindo, assim, ampla margem de escolha e, por consequência, o atendimento do melhor interesse dos empregados para o seu descanso.

Neste mesmo sentido, aliás, é criticável a alteração que determinou a vedação ao início do período de férias nos 2 (dois) dias que antecedem feriado ou dia de repouso semanal remunerado. A pretexto de favorecer os trabalhadores (mas sem custos aos empregadores), criou-se uma regra que, na prática, mais dificulta a marcação das férias e que pode vir inclusive 
a prejudicar os projetos de determinados empregados.

Por fim, quanto à revogação do impedimento ao fracionamento das férias dos trabalhadores menores de 18 (dezoito) anos e maiores de 50 (cinquenta) anos de idade, trata-se, como visto, de uma regra protetiva existente há muito tempo na CLT, baseada na pretensa vulnerabilidade destes grupos e vantagens do não-fracionamento. Entendemos que, aqui, também não houve prejuízo considerável ao trabalhador, pois a sociedade e a forma de trabalhar, hoje, são consideravelmente diferentes das de outrora, não sendo recomendável uma vedação ao fracionamento, sobretudo quando este é uma escolha do empregado (que pode optar por não fazê-lo).

Uma síntese desta evolução legislativa apresentada até o presente momento pode ser visualizada na Tabela 3 anexa ao final deste trabalho.

\section{CONCLUSÃO}

Esse trabalho buscou oferecer um panorama histórico-evolutivo do direito de férias desde o seu nascimento no mundo, passando então ao cenário do Brasil. No âmbito interno, a análise se estendeu desde a sua criação, como benefício espontâneo e voluntário, em fins do século XIX, e culminou nos dias atuais, já como um direito consolidado, alterado pontualmente pela reforma trabalhista da Lei $\mathrm{n}^{\circ} 13.467 / 17$. O estudo desse percurso legislativo, forneceu uma percepção que julgamos relevante.

É possível notar que, sobretudo durante o século XX, a trajetória do direito de férias no Brasil foi de progressiva melhora para os trabalhadores. Todavia, esta evolução sempre se deu sob determinados contextos, e, talvez, por isso, as alterações ocorreram de forma controlada, produzindo resultados de características limitadas. Explica-se:

Primeiramente, quanto ao contexto, percebe-se que, tanto no grande avanço da previsão celetista como na fase de incremento posterior do DL $\mathrm{n}^{\circ} 1.535 / 77$, focada na reorganização e detalhamento de certas regras, as alterações se deram sob governos ditatoriais (Estado Novo de Vargas e Ditadura Militar de Geisel, respectivamente).

Daí que não houve espaço para discussão, muito menos modificação, das bases originais do direito. Verifica-se que as alterações foram se dando ao longo do tempo, majoritariamente sobre aspectos anteriores, reproduzindo um viés autoritário e tutelar estatal.

Ou seja, a natureza da evolução do direito de férias no Brasil foi de apropriação do processo pelo governo, que, de maneira controlada e restrita, foi conferindo melhoria de alguns aspectos específicos do direito.

Nesse sentido, vimos que após a afirmação das férias como direito pela CLT original de 1943, o que se deu em tempo e bases até vanguardistas no Brasil comparativamente ao resto do mundo, já se garantiam 15 (quinze) dias úteis de férias remuneradas aos empregados, após um período aquisitivo de 1 (um) ano, sendo vedada a acumulação de períodos. Já havia, também, hipóteses de faltas justificadas, bem como a permissão de fracionamento em até 2 (dois) períodos, sendo que o principal tinha duração mínima de 7 (sete) dias. Analisando hoje, em retrospecto, estes direitos, após o longo período de tempo transcorrido, nota-se um avanço localizado sobretudo quanto aos prazos, e não inovações propriamente ditas.

Até houve aperfeiçoamentos importantes em alguns momentos, como com o DL n ${ }^{\circ}$ $1.535 / 77$, que criou o aviso antecedente das férias, cujo prazo foi posteriormente aumentado pela Lei $n^{\circ} 7.414 / 85$ para 30 (trinta) dias, permitindo ao trabalhador uma melhor organização para o seu descanso; também a criação da penalidade do pagamento em dobro em caso de não concessão das férias na data correta. Ou, ainda, posteriormente, a previsão do terço de férias pela Constituição de 1988, que ofereceu ganho extra para o trabalhador desfrutar o período.

No cotejo com os dias atuais, inclusive após a última reforma de 2017, não há, portanto, 
como se falar em diferença substancial, mas mera ampliação, até tímida, de certas regras ou prazos, como foi o caso da nova possibilidade de 3 (três) fracionamentos e aumento da duração mínima do período principal para 14 (quatorze) dias corridos. Não foram modificados aspectos centrais a este direito e que poderiam melhorar efetivamente a qualidade do repouso anual dos trabalhadores. Oferecemos alguns exemplos: a decisão pela época das férias passar a ser influenciada ou até decidida pelos empregados; a garantia, em todos os casos, de contabilização no período aquisitivo do tempo que o empregado deixou de trabalhar por motivos estranhos à sua vontade (ex.: acidente de trabalho); ou, ainda, a previão de que as férias sejam contadas em dias úteis e não em dias corridos. Estas, aliás, são garantias previstas na Convenção 132 da OIT.

Outras possibilidades de incremento neste direito seriam: a previsão de um aumento progressivo do período de férias conforme a permanência do empregado junto de um mesmo empregador, como ocorre em outros países, inclusive da América Latina, medida esta que tem potencial de reduzir a rotatividade, melhorando a gestão do conhecimento nas empresas; a possibilidade dos empregados poderem decidir efetivamente, sem limitações legais, quantos fracionamentos ou, até, quantos dias por período desejam descansar, privilegiando sua autonomia na definição do descanso e a flexibilidade; a eventual vedação ao abono pecuniário, como forma de privilegiar o descanso em detrimento do capital; a possibilidade de férias não remuneradas como um direito aos empregados, permitindo que estes eventualmente pudessem vir a retirar anos sabáticos ou se dedicar a outros projetos, assumindo os custos; a previsão de mecanismos legais inovadores, fortes e eficientes, visando o respeito ao direito de férias, que infelizmente ainda é descumprido em diversos locais e oportunidades.

Portanto, o quadro delineado pelo presente estudo é de que a evolução histórica do direito de férias no Brasil não foi propriamente negativa aos trabalhadores, mas ficou longe de ter oferecido as melhorias esperadas e que seriam plenamente possíveis ao trabalhador brasileiro. Não se inovou. Não foram conduzidas melhorias relevantes no direito de férias, algo que poderia ser benéfico sob diversos aspectos para os atores envolvidos e para o país, como por exemplo, para fins de satisfação dos trabalhadores, desenvolvimento do setor de cultura e lazer, diminuição dos gastos públicos com acidentes de trabalho e saúde, produtividade das empresas e riqueza nacional.

\section{Referências}

ANTUNES, Ricardo L. C. O que é sindicalismo. Coleção Primeiros Passos. 10 ${ }^{a}$ Edição. São Paulo: Editora Brasiliense, 1985.

BARROS, Cassio Mesquita de. Democratização das Relações de Trabalho. Revista de Direito do Trabalho. vol. 103/2001. p. 44 - 52. Jul - Set. 2001.

BEAUD, Michel. História do Capitalismo: De 1500 aos nossos dias. $5^{\text {a }}$ edição, São Paulo: Editora Brasiliense, 2005.

BRASIL. Constituição da República Federativa do Brasil, de 05 de out. de 1988. Brasília, DF.

Constituição da República dos Estados Unidos do Brasil, de 16 de jul. de 1934. Brasília, DF.

Decreto $\mathrm{n}^{\circ}$ 16.027, de 30 de abr. de 1923. Cria o Conselho Nacional do Trabalho. Rio de Janeiro, RJ. 
Decreto $\mathrm{n}^{\circ} 19.770$, de 19 de mar. de 1931. Regula a sindicalisação das classes patronaes e operarias e dá outras providências. Rio de Janeiro, RJ.

Decreto $\mathrm{n}^{\circ} 19.808$, de 28 de mar. de 1931. Suspende a execução da Lei $\mathbf{n}^{\mathbf{0}}$ 4.982, de 24 de dez. de 1925, respectivo regulamento, e estabelece nova modalidade para a concessão de férias a operários e empregados. Rio de Janeiro, RJ.

Decreto $\mathrm{n}^{\mathbf{0}}$ 23.103, de 19 de ago. de 1933. Regula a concessão de férias aos empregados em estabelecimentos comerciais e bancarios e em instituições de assistencia privada. Rio de Janeiro, RJ.

Decreto $\mathrm{n}^{\mathbf{0}} 23.768$, de 18 de jan. de 1934. Regula a concessão de férias aos empregados na indústria, sindicalizados. Rio de Janeiro, RJ.

. Decreto-Lei no 5.452, de 01 de mai. de 1943. Consolidação das Leis do Trabalho. Rio de Janeiro, RJ.

Decreto-Lei $\mathrm{n}^{\circ} 1.535$, de 15 de abr. de 1977. Altera o Capítulo IV do Título II da Consolidação das Leis do Trabalho, relativo a Férias, e dá outras providências. Brasília, DF.

Decreto Presidencial no 3.197, de 05 de out. de 1999. Promulga a Convenção no 132 da Organização Internacional do Trabalho sobre Férias Anuais Remuneradas (revista em 1970), concluída em Genebra, em 24 de junho de 1970. Brasília, DF.

Lei ${ }^{\circ}$ 4.982, de 24 de dez. de 1925. Manda conceder, anualmente, 15 dias de férias aos empregados e operarios de estabelecimentos commerciaes, industriaes e bancarios, sem prejuizo de ordenado, vencimentos ou diarias e dá outras providencias. Rio de Janeiro, RJ.

. Lei no 816 , de 09 de set. de 1949. Dá nova redação aos artigos 132 e 134, do Decretolei $\mathbf{n}^{\circ}$ 5.452, de $1^{\circ}$ de maio de 1943. Rio de Janeiro, RJ.

. Lei $\mathrm{n}^{\circ} 7.414$, de 09 de dez. de 1985. Altera a redação do art. 135 da Consolidação das Leis do Trabalho, aprovada pelo Decreto-lei $n^{\circ} 5.452$, de $1^{\circ}$ de maio de 1943 , que dispõe sobre a concessão das férias anuais remuneradas. Brasília, DF.

Lei $\mathrm{n}^{\circ} 13.467$, de 13 de jul. de 2017. Altera a Consolidação das Leis do Trabalho e as Leis $n^{0}$ 6.019, de 3 de janeiro de 1974, 8.036, de 11 de maio de 1990, e 8.212, de 24 de julho de 1991, a fim de adequar a legislação às novas relações de trabalho. Brasília, DF.

CASS AR, Vólia Bonfim. Direito do Trabalho. 5ª Edição. Niterói: Editora Impetus, 2011.

CIDH ORG, 2017. Protocolo adicional à convenção americana sobre direitos humanos em matéria de direitos econômicos, sociais e culturais, "protocolo de San Salvador". Disponível em: http://www.cidh.org/basicos/portugues/e.protocolo de san salvador.htm. Acesso em: 11/01/2018.

COIMBRA, Rodrigo. Fundamentos e evolução histórica dos limites da duração de trabalho. 
Revista de Direito do Trabalho. vol. 158/2014, p. 117 - 141. Jul - Ago, 2014.

DA SILVEIRA, Sheila Stolz. O direito fundamental a férias anuais remuneradas desde a perspectiva do direito comunitário europeu. Análise de uma sentença judicial do Tribunal de Justiça das Comunidades Européias - TJCE. In: Âmbito Jurídico, Rio Grande, IX, n. 31, jul 2006. Disponível em: http://www.ambitojuridico.com.br/site/index.php?n link=revista artigos leitura\&artigo id=1658. Acesso em: $25 / 11 / 2017$

DELGADO, Maurício Godinho. Curso de Direito do Trabalho. $8^{\text {a }}$ Edição. Rio de Janeiro: Editora LTr, 2009.

DUPPER, Ockert. Jurista sul-africano Ockert Dupper fala sobre a Organização Internacional do Trabalho em seminário no TRT-RS. Disponível em: https://www.trt4.jus.br/portais/trt4/modulos/noticias/99750. Acesso em: 07/12/2015.

GIGLIO, Wagner D. Férias e Descansos Remunerados. $4^{\text {a }}$ Edição. São Paulo: Editora LTr, 1978.

HOBSBAWM, Eric J. Da Revolução Industrial Inglesa ao Imperialismo. $4^{\mathrm{a}}$ Edição. Rio de Janeiro: Editora Forense-Universitária, 1986.

MARTINS, Sergio Pinto. Breve histórico a respeito do Trabalho. Revista da Faculdade de Direito de São Paulo. v.95. USP, São Paulo. 2000. Disponível em: http://www.revistas.usp.br/rfdusp/article/viewFile/67461/70071. Acesso em: 11/01/2018.

MARTINS, Sérgio Pinto. Direito do trabalho. 24a Edição. São Paulo: Editora Atlas, 2008.

MONTEIRO, M.S.; GOMES, J.R. De Taylor ao modelo japonês: modificações ocorridas nos modelos de organização do trabalho e a participação no trabalho. Revista Brasileira de Saúde Ocupacional - no 93/94, vol. 25, 1998.

NAÇÕES UNIDAS BR. Declaração Universal dos Direitos Humanos, de 10 de dez. de 1948. Disponível em: https://nacoesunidas.org/direitoshumanos/declaracao/. Acesso em: 10/12/2017

. Pacto Internacional sobre Direitos Econômicos, Sociais e Culturais, de 16 de dez. de 1966. Disponível em: http://www.unfpa.org.br/Arquivos/pacto_internacional.pdf. Acesso em: 10/12/2017

NUNES, G. Machado. Ócio e lazer na regulamentação das férias operárias: a OIT e o caso brasileiro na primeira metade do século XX. Anuario del Instituto de Historia Argentina, 17(1), e033. 2017. Disponível em: https://doi.org/10.24215/2314257Xe033. Acesso em: 01/11/2017.

OIT BRASILIA. Convenções. Disponível em: http://www.ilo.org/brasilia/convencoes/ lang-pt/index.htm. Acesso em: 01/11/2017.

Informações e História da OIT. Disponível em: http://www.ilo.org/brasilia/centrode-informacoes/lang--pt/index.htm. Acesso em: 01/11/2017. 
RUSSOMANO, Mozart Victor. Curso de Direito do Trabalho. $9^{\text {a }}$ Edição. Curitiba: Editora Juruá, 2006.

SÜSSEKIND, Arnaldo. Comentários à nova Lei de Férias. São Paulo: LTr, 1977. TST.

TRIBUNAL SUPERIOR DO TRABALHO. Índice de Súmulas. Enunciado $\mathbf{n}^{\mathbf{1}} \mathbf{1 7 1}$ Disponível em: http://www.tst.jus.br/sumulas. Acesso em: 02/12/2017.

Recebido em 28 de fevereiro de 2018. Aceito em 20 de maio de 2019. 


\section{ANEXO}

TABELA 1

EVOLUÇÃO HISTÓRICA DO DIREITO DE FÉRIAS NO BRASIL - ANTES DA CLT

\begin{tabular}{|c|c|c|c|c|}
\hline $\begin{array}{c}\text { PERÍODO } \\
\text { HISTÓRICO } \\
\text { ANTES DA } \\
\text { CLT } \\
\rightarrow\end{array}$ & $\begin{array}{l}\text { Lei no } 4.982 / 1925 \\
\text { (Governo Artur } \\
\text { Bernardes) }\end{array}$ & $\begin{array}{c}\text { Decreto no } 19.808 / 1931 \\
\text { (Governo Getúlio } \\
\text { Vargas) }\end{array}$ & $\begin{array}{c}\text { Decreto no } \\
23.768 / 1934 \\
\text { (Governo Getúlio } \\
\text { Vargas) }\end{array}$ & $\begin{array}{c}\text { Constituição de } \\
1934 \\
\text { (Governo } \\
\text { Getúlio Vargas) }\end{array}$ \\
\hline $\begin{array}{l}\text { ALTERAÇÕES/ } \\
\text { INOVAÇÕES } \\
\rightarrow\end{array}$ & $\begin{array}{l}\text { Garantiu a todos os } \\
\text { trabalhadores } \\
\text { urbanos o direito a } \\
15 \text { (quinze) dias de } \\
\text { férias remuneradas } \\
\text { anuais }\end{array}$ & $\begin{array}{l}\text { Suspendeu a execução } \\
\text { da Lei no } 4.982 / 1925 . \\
\text { Houve o retorno ao } \\
\text { estágio antecedente dos } \\
\text { particularismos por } \\
\text { categoria (comerciários, } \\
\text { industriais etc.) }\end{array}$ & $\begin{array}{l}\text { Voltou a conceder o } \\
\text { direito de férias à várias } \\
\text { categorias distintas, } \\
\text { porém exigia a } \\
\text { sindicalização dos } \\
\text { empregados para se } \\
\text { fazer jus ao direito }\end{array}$ & $\begin{array}{l}\text { Constitucionaliza } \\
\text { ção do Direito no } \\
\text { Brasil }\end{array}$ \\
\hline
\end{tabular}

TABELA 2

EVOLUÇÃO HISTÓRICA DO DIREITO DE FÉRIAS NO BRASIL - PÓS CLT

\begin{tabular}{|c|c|c|c|}
\hline $\begin{array}{c}\text { PERÍODO } \\
\text { HISTÓRICO } \\
\text { PÓS-CLT } \\
\rightarrow \\
\rightarrow\end{array}$ & $\begin{array}{c}\text { Lei no 5.452/1943 (CLT) } \\
\text { (Governo Getúlio Vargas - } \\
\text { Estado Novo) }\end{array}$ & $\begin{array}{l}\text { Lei no 816/1949 } \\
\text { (Governo } \\
\text { Dutra) }\end{array}$ & $\begin{array}{l}\text { Decreto-Lei no 1.535/1977 } \\
\text { (Governo Geisel) }\end{array}$ \\
\hline $\begin{array}{l}\text { ALTERAÇÕES/ } \\
\text { INOVAÇÕES } \\
\rightarrow\end{array}$ & $\begin{array}{l}\text { - Garantiu o direito à férias } \\
\text { também aos rurais. } \\
\text { - } 15 \text { (quinze) dias úteis de } \\
\text { férias aos empregados, } \\
\text { após período aquisitivo } \\
\text { de } 12 \text { (doze) meses; } \\
\text { - Gozo das férias } \\
\text { necessariamente nos } 12 \\
\text { (doze) meses seguintes à } \\
\text { aquisição (período } \\
\text { fruitivo); } \\
\text { - Vedação à acumulação } \\
\text { de períodos; } \\
\text { - Fracionamento de até } 2 \\
\text { (dois) períodos, sendo } \\
\text { um deles não inferior a } 7 \\
\text { (sete) dias; } \\
\text { - Definição da época do } \\
\text { gozo à critério do } \\
\text { empregador; } \\
\text { - Férias em período único } \\
\text { para menores de } 18 \\
\text { (dezoito) e maiores de } 50 \\
\text { (cinquenta) anos de } \\
\text { idade; } \\
\text { - Concessão das férias por } \\
\text { escrito, mediante recibo, } \\
\text { com antecedência de, no } \\
\text { mínimo, } 8 \text { (oito) dias; }\end{array}$ & $\begin{array}{l}\text { - Ampliação } \\
\text { do número } \\
\text { de dias de } \\
\text { férias - } 20 \\
\text { (vinte) dias } \\
\text { úteis, desde } \\
\text { que não } \\
\text { houvesse } \\
\text { quaisquer } \\
\text { faltas; } \\
\text { - Ampliação } \\
\text { do rol de } \\
\text { faltas } \\
\text { justificadas; }\end{array}$ & $\begin{array}{l}\text { - Reorganização do tema na CLT, } \\
\text { influenciada pela Convenção 132, OIT; } \\
\text { - Período de férias passou a ser de } 30 \\
\text { (trinta) dias corridos, desde que não } \\
\text { houvesse faltas; } \\
\text { - Faltas justificadas deixam de ser } \\
\text { computadas como faltas no período } \\
\text { aquisitivo; } \\
\text { - Na repartição do período concessivo } \\
\text { em dois, um deles passa a não poder } \\
\text { ter menos de } 10 \text { (dez) dias corridos } \\
\text { - O aviso de férias ao empregado é } \\
\text { ampliado para } 10 \text { (dez) dias de } \\
\text { antecedência; } \\
\text { - Garantia ao empregado menor de } 18 \\
\text { (dezoito) anos de fazer coincidir suas } \\
\text { férias com as férias escolares; } \\
\text { - Especificação de penalidades pela não } \\
\text { concessão das férias no prazo oportuno } \\
\text { (pagamento em dobro da } \\
\text { remuneração); } \\
\text { - Normativa das férias coletivas; } \\
\text { - Previsão do abono de férias } \\
\text { (possibilidade de conversão de } 1 / 3 \text { das } \\
\text { férias em pecúnia); } \\
\text { - Pagamento das férias antecedente } 2 \\
\text { (dois) dias ao seu início; }\end{array}$ \\
\hline
\end{tabular}


TABELA 3

EVOLUÇÃO HISTÓRICA DO DIREITO DE FÉRIAS NO BRASIL - PÓS CONSTITUIÇÃO DE 1988

\begin{tabular}{|c|c|c|}
\hline $\begin{array}{c}\text { PERÍODO } \\
\text { HISTÓRICO } \\
\text { PÓS CONSTITUIÇÃO } \\
\text { DE } 1988 \\
\rightarrow\end{array}$ & $\begin{array}{l}\text { Constituição Federal de } 1988 \\
\text { (Governo Sarney) }\end{array}$ & $\begin{array}{l}\text { Lei no 13.467/2017 - Reforma Trabalhista } \\
\text { (Governo Temer) }\end{array}$ \\
\hline $\begin{array}{c}\text { ALTERAÇÕES/ } \\
\text { INOVAÇÕES } \\
\rightarrow\end{array}$ & $\begin{array}{l}\text { - Previsão das férias como um } \\
\text { direito social (art.7 }, \quad \text { XVII), } \\
\text { inserido no título dos direitos e } \\
\text { garantias fundamentais do } \\
\text { cidadão; } \\
\text { - Previsão do terço constitucional } \\
\text { de férias; }\end{array}$ & $\begin{array}{l}\text { - Ampliação do tempo de férias dos } \\
\text { trabalhadores empregados em tempo } \\
\text { parcial, que passaram a gozar também de } \\
30 \text { (trinta) dias de férias como os demais } \\
\text { empregados e direito ao abono pecuniário } \\
\text { (possibilidade de venda de } 1 / 3 \text { do } \\
\text { período); } \\
\text { - Possibilidade de fracionamento das férias } \\
\text { em até } 3 \text { períodos, a critério do } \\
\text { empregado; } \\
\text { - Ampliação do período mínimo de gozo de } \\
\text { férias, devendo o principal ser de no } \\
\text { mínimo } 14 \text { (quatorze) dias corridos e os } \\
\text { demais de } 5 \text { (cinco) dias corridos cada um } \\
\text { (no caso de triplo fracionamento); } \\
\text { - Vedação do início do período de férias nos } \\
2 \text { (dois) dias que antecedem feriado ou o } \\
\text { dia de repouso semanal remunerado; } \\
\text { - Liberação do particionamento das férias } \\
\text { por trabalhadores menores de } 18 \text { (dezoito) } \\
\text { anos e maiores de } 50 \text { (cinquenta) anos de } \\
\text { idade; }\end{array}$ \\
\hline
\end{tabular}

